\title{
Laboreal
}

Volume $16 \mathrm{~N}^{\circ} 1 \mid 2020$

Quando o trabalho real é tabu

\section{8 de febrero de 2002: las sentencias "amianto" del Tribunal Supremo de Justicia de Francia redefinen la falta inexcusable del empleador}

28 de fevereiro de 2002: os acórdãos 'amianto' do Supremo Tribunal de Justiça da França redefinem a falta indesculpável do empregador

28 février 2002 : les arrêts " amiante »: la cour de Cassation française re-

définit la faute inexcusable de l'employeur

February 28, 2002: the 'asbestos' decisions of the French Supreme Court redefine the inexcusable fault of the employer

\section{Annie Thébaud-Mony}

Traductor. Fernanda Romero

\section{(2) OpenEdition}

\section{Journals}

Edición electrónica

URL: http://journals.openedition.org/laboreal/16213

DOI: 10.4000/laboreal.16213

ISSN: 1646-5237

Editor

Universidade do Porto

\section{Referencia electrónica}

Annie Thébaud-Mony, " 28 de febrero de 2002: las sentencias "amianto" del Tribunal Supremo de Justicia de Francia redefinen la falta inexcusable del empleador », Laboreal [En línea], Volume $16 \mathrm{~N}^{0} 1$ । 2020, Publicado el 01 julio 2020, consultado el 19 septiembre 2020. URL : http://

journals.openedition.org/laboreal/16213; DOI : https://doi.org/10.4000/laboreal.16213

Este documento fue generado automáticamente el 19 septiembre 2020.

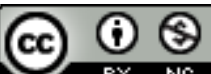

Laboreal está licenciado com uma Licença Creative Commons - Atribuição-NãoComercial 4.0 Internacional. 


\section{8 de febrero de 2002: las sentencias "amianto" del Tribunal Supremo de Justicia de Francia redefinen la falta inexcusable del empleador}

28 de fevereiro de 2002: os acórdãos 'amianto' do Supremo Tribunal de Justiça da França redefinem a falta indesculpável do empregador

28 février 2002 : les arrêts " amiante " : la cour de Cassation française re-

définit la faute inexcusable de l'employeur

February 28, 2002: the 'asbestos' decisions of the French Supreme Court redefine the inexcusable fault of the employer

Annie Thébaud-Mony

Tradución : Fernanda Romero

\section{NOTA DEL EDITOR}

Traducción : Fernanda Romero - fernandaromero.trad@gmail.com

1 El movimiento social de las víctimas del amianto en Francia ha pasado por dos fases de movilización, determinantes para el reconocimiento social y político de la catástrofe sanitaria causada por esas fibras minerales.

2 La primera fase ocurrió en la década de 1970, cuando científicos que trabajaban en los laboratorios del campus universitario de Jussieu, en Paris, al percibir la extensión de la contaminación causada por el amianto flocado existente en los edificios, iniciaron una lucha por su seguridad. En simultaneo, llevaron a cabo un trabajo de información con el fin de apoyar la movilización de los trabajadores de las fábricas de amianto y recopilaron en una obra bien documentada todos los conocimientos que existían 
entonces sobre los peligros mortales que esa fibra representa (Collectif intersyndical Sécurité des Universités Jussieu, 1977).

3 En esa época, se han adoptado dos medidas políticas: la inclusión del mesotelioma (cáncer de la pleura, típico de la exposición al amianto) en la tabla n. ${ }^{\circ} 30$ de las enfermedades profesionales causadas por el amianto y la aprobación del decreto del 17 de agosto de 1977 que establecía un valor límite de exposición (VLE), que ya entonces se consideraba inadecuado. En efecto, el informe de una reunión de expertos sobre cuestiones relacionadas con el amianto de la Oficina Internacional del Trabajo (BIT), celebrada en diciembre de 1973, ya mencionaba que el VLE de $2 \mathrm{f} / \mathrm{cm}^{3}$ debería considerarse un "objetivo provisional" de prevención de los riesgos, una vez que "se aplica a los efectos fibrogénicos del amianto y no a los efectos carcinogénicos, respecto a los cuales no existe actualmente ningún valor" (BIT, 1973).

4 La segunda fase de movilización, que va de 1994 a la primera década de 2000, fue la fase de la lucha por la prohibición del amianto en Francia, por la adopción de medidas de seguridad en la gestión del amianto ya colocado y por la mejoría de las condiciones de indemnización de las víctimas, empezando por los trabajadores. La prohibición fue lograda en julio de 1996, con efectos a partir del 1 de enero de 1997. Se crearon, entonces, distintas asociaciones y comisiones locales que tenían como prioridad la lucha por el reconocimiento de los daños causados a las víctimas. El objetivo de las distintas fuerzas involucradas en esta lucha (asociaciones de víctimas, científicos, abogados, médicos, agentes de prevención) era obtener justicia para las víctimas. En Francia, el amianto ha causado más de 3000 muertes por año desde la década de 1990, algo que se mantiene todavía hoy.

5 Estas sentencias representan una de las más grandes victorias judiciales logradas por la movilización social para el reconocimiento de los daños sufridos por las víctimas del amianto, ya que su ámbito abarca no solo las indemnizaciones, sino también la prevención.

\section{Un principio de justicia: reconocer la falta inexcusable del empleador}

6 Hasta las demandas interpuestas por las víctimas del amianto en la década de 1990, y según una jurisprudencia antigua [1], después de haberle sido reconocida una enfermedad profesional, la víctima podría alegar "falta inexcusable del empleador" siempre y cuando presentase pruebas de que una falta de "excepcional gravedad" (en particular la violación de los reglamentos de seguridad) había sido el origen del accidente de trabajo o enfermedad profesional (AT/EP). En la práctica, ese procedimiento que hubiera permitido una indemnización, digna de ese nombre, a las víctimas de AT/EP - o sea, semejante a la que la ley establece en caso de la llamada indemnización "integral" en derecho civil - casi nunca era aplicado para las enfermedades profesionales.

7 En tiempos todavía más lejanos, una sentencia del 27 de noviembre de 1884, "Jean Thommes", caída en el olvido, había creado la "obligación de seguridad y de resultado". Esa sentencia reconocía la culpa del empleador que no hubiese garantizado la seguridad del trabajador, si el accidente demostrase la inexistencia de un dispositivo de prevención (Sargos, 2015). Surgirá, después, una ley cuya piedra angular será esa obligación. De 
hecho, al iniciar la legislación laboral en materia de higiene y seguridad, la ley de 12 de julio de 1893 refiere la cuestión de los polvos cuando define la obligación de seguridad y de resultado: "el aire de los talleres se renovará de modo a mantenerse en el estado de pureza indispensable para la salud de los obreros". Esta obligación de seguridad del dueño de la empresa figura todavía hoy en el código del Derecho del Trabajo [2]. La directiva marco europea de 1989 sobre la salud de los trabajadores, transpuesta al derecho francés [3], refuerza aún más la actualidad de esa obligación, y la entidad patronal está obligada a garantizar su eficacia, lo que permite, de este modo, considerar que una violación de esta regla constituye una falta inexcusable del empleador.

8 En el caso de los trabajadores víctimas del amianto, la falta inexcusable del empleador surge a los ojos de los abogados y de las asociaciones como totalmente legítima. Apoyados por las asociaciones, e igualmente por abogados y científicos, los trabajadores víctimas de enfermedades causadas por el amianto, o sus familias en caso de muerte de estos, presentaron al Tribunal de Asuntos de Seguridad Social (TASS), desde la década de 1990, varias decenas de demandas. Hablamos de antiguos obreros de las fabricas ETERNIT (fibrocemento), AMISOL (textiles con amianto), pero también de los que trabajaron para grandes utilizadores de amianto como la siderurgia (ASCOMETAL) y astilleros navales. Por supuesto que los industriales interponían recursos y las demandas judiciales acabarían por llegar al Tribunal Supremo, cuya sección social, son solemnidad, emitió, el 28 de febrero de 2002, 29 sentencias "amianto".

\section{Amianto: obligación de resultado y error inexcusable}

En los fundamentos de cada una de esas sentencias (Teissonnière \& Topaloff, 2002), la sección social del Supremo retoma el principio de obligación de seguridad y de resultado: "en virtud de su contrato de trabajo que lo vincula a su asalariado, el empleador tiene para con este una obligación de seguridad y de resultado, en particular en lo que respecta a las enfermedades profesionales contraídas por el asalariado debido a productos fabricados o utilizados por la empresa". Después de haber redefinido esa obligación, esa jurisprudencia reconoce la infracción como error inexcusable: "el no cumplimiento de esa obligación por parte del empleador, asume el carácter de falta inexcusable de conformidad con el artículo L. 452-1 del Código de Seguridad Social, cuando el empleador tenía o debería haber tenido la consciencia del peligro a que el asalariado estaba expuesto y no adoptó las medidas de prevención necesarias para con él".

10 Ya no se trata, por consiguiente, de calificar un "error de extrema gravedad" (prácticamente imposible de probar). A partir del 28 de febrero de 2002, la consciencia de riesgo que el empleador tiene o debería haber tenido se convirtió en el primer criterio para reconocer una falta inexcusable en materia de enfermedades profesionales. En las demandas judiciales presentadas al Supremo, los abogados pudieron apoyarse en el conjunto de pruebas del conocimiento que las empresas francesas tenían desde la época lejana en la que se estableció el principio fundamental de obligación de seguridad y de resultado del empleador.

11 En efecto, el amianto se enmarca en la categoría de "polvos", de conformidad con la ley del 12 de junio de 1893 y de los decretos que definían la aplicación de sus disposiciones, todavía incluidas en el Código del Trabajo. Sin embargo, y más precisamente, los primeros indicios de la toxicidad del amianto remontan, en Francia, a 1906, con la publicación de un artículo del inspector de trabajo Denis Auribault sobre las muertes 
ocurridas en la fábrica Ferodo (una filial de la empresa inglesa Turner and Newal) en Normandía (Auribault, 1906). Posteriormente, varios artículos médicos publicados, concretamente de medicina del trabajo, llaman la atención para las consecuencias del amianto en la salud (entre las décadas 1930 y 1960). La referencia al amianto en una tabla de enfermedades profesionales remonta a 1946, antes de la creación, en 1950, de la tabla de EP n. 30 , específica del amianto. Por fin, los industriales franceses (y los médicos que colaboraban con ellos para minimizar los riesgos de las fibras del amianto) participaron en la "Conferencia Internacional de las Organizaciones de Información del Amianto", celebrada en Londres en 1971, por iniciativa de las empresas relacionadas con ese sector, con la finalidad de retrasar, lo más posible, la divulgación de los conocimientos sobre los peligros del amianto para la salud que pudieran conducir a reglamentaciones rigurosas (Thébaud-Mony, 2014, p. 61-62). Las conclusiones a que llegaron esos industriales después de esta conferencia, llevarían a la creación, por iniciativa de ellos mismos, del Comité Permanente del Amianto que aseguraría la difusión del mito de la "utilización controlada del amianto" del inicio de la década de 1980 hasta la decisión de la prohibición del amianto en Francia, diecisiete años después.

Todos estos hechos llamaron la atención de los jueces y condujeron a una evolución de la jurisprudencia en materia de falta inexcusable del empleador, favorable no solo a la indemnización de los trabajadores víctimas del amianto, sino también a la preservación con base en el fundamento de "obligación de seguridad y de resultado". Tan pronto surgen las enfermedades causadas por el amianto, la insuficiencia y la inadecuación de las medidas adoptadas por el empleador, o la ausencia de estas, prueban el no cumplimiento por el empleador de la obligación que le incumbe.

\section{Una estrategia judicial relegada a un segundo plano debido a la creación del Fondo de Indemnización de las Víctimas del Amianto (FIVA)}

13 Esta decisión judicial surgió en Francia, en la época en que la ley de la financiación de la seguridad social de 2000 había creado el FIVA, la entidad responsable por el pago de una indemnización más elevada a las víctimas profesionales y medioambientales [4]. Esta iniciativa legislativa había sido apoyada políticamente por el patronato, para quién ese Fondo podría representar una forma de separar las víctimas del amianto de las otras víctimas laborales y de reducir el potencial ámbito de la falta inexcusable del empleador, cada vez más reconocida por los tribunales de apelación, incluso antes de una decisión del Supremo. Una parte del movimiento social de defensa de las víctimas del amianto había sido seducida por la supuesta rapidez de las demandas de indemnización del FIVA, aunque hubiera quien le fuese hostil y rechazase, como fue el caso de las antiguas obreras de AMISOL, "cambiar la justicia por un cheque" (ThébaudMony, 2007, p. 69-70).

14 De hecho, la contradicción persiste desde 1898 con la aprobación de la ley sobre accidentes de trabajo que reconoce el derecho de indemnización a las víctimas de accidentes de trabajo, independientemente de la causa, lo que tiende a banalizar los riesgos del trabajo en detrimento de la necesidad de prevención.

No obstante, la ley que crea el FIVA incluye un artículo que establece que el Fondo puede actuar judicialmente en sustitución de la víctima de enfermedad profesional 
causada por el amianto para obtener reconocimiento de la falta inexcusable del empleador infractor [5]. Sin embargo, esta disposición ha sido poco aplicada: en 2017, de los 338,70 millones de euros pagados en indemnizaciones, el FIVA ha recuperado solamente 23,20 millones en acciones subrogatorias en los tribunales de seguridad social. Con todo, el $72 \%$ de las personas indemnizadas lo son por enfermedad profesional, lo que hace creer que el contencioso por falta inexcusable debería ser mucho mayor. Al contrario de las decisiones judiciales, como las del 28 de febrero de 2002, los informes del FIVA no han relevado los nombres de los culpables y no permitieron saber cuáles son las grandes empresas - como ETERNIT, ASCOMETAL o los astilleros navales - cuyos asalariados víctimas del amianto podrían haber alegado falta inexcusable del empleador, obligando a que este asumiese los costes. De esta forma, las responsabilidades de los empleadores se mantienen totalmente ocultas.

\section{Conclusión}

16 La mayoría de las víctimas del amianto acudió al FIVA, animada por distintas asociaciones, médicos y cajas de seguro de enfermedad. El efecto de las emblemáticas sentencias de febrero de 2002 no se ha traducido, por lo tanto, en un esperado contencioso masivo de las víctimas laborales del amianto lo que, por su parte, podría haber sido un incentivo para las víctimas de otros riesgos del trabajo.

En lo que respecta a la prevención en el lugar de trabajo, poco tiene que ver con el contenido de la olvidada sentencia del 27 de noviembre de 1884, sobre la cual Pierre Sargos, presidente de la sección social del Supremo en el momento de las sentencias del amianto, afirmó tratarse de la "sentencia más importante alguna vez pronunciada por un tribunal de última instancia en materia de protección de la seguridad de los trabajadores y de denuncia de los daños causados por una actitud explotadora en perjuicio de la vida ajena" (Sargos, 2015, p. 2179).

Esa "actitud explotadora" de que Pierre Sargos habla está en el origen del desastre sanitario del amianto, así como en el de muchos otros semejantes (pesticidas, radioactividad, alteradores endocrinos, etc.).

19 Ha sido también esa mentalidad que generó la crisis que ahora vivimos, estando la obligación de la "rentabilidad" de los hospitales en el origen de las graves carencias sentidas en las últimas semanas en la lucha contra los riesgos de la infección por COVID-19. La ministra francesa del trabajo, cuando se refirió a la necesidad de retomar la construcción civil durante la epidemia de COVID-19, independientemente de los riesgos, se pronunció públicamente contra los fundamentos del Código del Trabajo, ya con 125 años, al declarar que la obligación patronal de seguridad es una "obligación de medios" y no de "resultados" [6]. Para que los inspectores del trabajo, propensos a ser rigurosos con los empleadores en los que respecta las protecciones individuales necesarias para los trabajadores, entendieran bien el mensaje, la ministra suspendió uno de ellos, impidiéndolo de cumplir su misión, por no haber respectado "de forma deliberada, grave y reiterada las instrucciones de la autoridad central del sistema de inspección del trabajo sobre las acciones de inspección durante la epidemia de COVID-19" [7].

20 Ante la magnitud de los accidentes causados por esa "actitud explotadora", lo que ocurrió en Francia con el amianto en las últimas décadas revela que las movilizaciones asociativas, sindicales y de la sociedad civil son cada vez más indispensables para la 
defensa de los derechos fundamentales de los trabajadores a la salud, a la dignidad y a la justicia.

\section{BIBLIOGRAFÍA}

Auribault, D. (1906). Note sur l'hygiène et la sécurité des ouvriers dans les filatures et tissage d'amiante, Bulletin de l'inspection du travail, 120-132.

BIT (1973). L'amiante, ses risques pour la santé et leur prévention. Réunion d'experts sur la sécurité dans l'utilisation de l'amiante. Genève: Bureau International du Travail, 11-18 décembre.

Collectif intersyndical Sécurité des Universités Jussieu (1977). Danger, Amiante! Paris: Maspero.

Sargos, P. (2015). Hygiène et sécurité du travail : qui se souvient de Jean Thommes? La semaine juridique générale, 49, 21, 2179-2186.

Teissonnière, J. P. \& Topaloff, S. (2002). L'affaire de l'amiante. Semaine sociale Lamy, Supplément $\mathrm{n}^{\circ} 1082,32 \mathrm{p}$.

Thébaud-Mony, A. (2007) Travailler peut nuire gravement à votre santé. Paris: La Découverte.

Thébaud-Mony, A. (2014). La science asservie. Santé publique: les collusions mortiferes entre industriels et chercheurs. Paris: La Découverte.

\section{NOTAS}

1. Jurisprudencia conocida como "Dame veuve Villa", del 15 de julio de 1941.

2. "El empleador adopta las medidas necesarias para garantizar la seguridad y proteger la salud física y mental de los trabajadores. (...)" (artículo L4121-1 del Code du travail).

3. Directiva 89/391/CEE del Consejo, del 12 de junio de 1989 relativa a la "aplicación de medidas para promover la mejoría de la seguridad y de la salud de los trabajadores en el trabajo" (https:// www.legifrance.gouv.fr/affichTexte.do?cidTexte=JORFTEXT000000333571\&categorieLien=i)

4. Artículo 53 de la Loi n $2000-1257$ del 23 diciembre de 2000 sobre la financiación de la seguridad social para 2001.

5. "El fondo es subrogado, hasta el límite de los importes pagados, en los derechos que el demandante tiene contra la persona responsable por el daño, bien como contra las personas u organizaciones obligadas, bajo cualquier título, a garantizar una indemnización total o parcial dentro de los límites del importe de las prestaciones a cargo de dichas personas." (Loi $\mathrm{n}^{\circ}$ 2000-1257 del 23 diciembre de 2000).

6. Muriel Pénicaud: "La ley prevé que ellos son responsables de crear medios de protección", explicó en el programa Le Grand Jury RTL/Figaro/LCI. E insistió: "No son responsables si alguien, más tarde, viene a enfermar, sino son responsables por los medios que han empleado".

7. https://www.asso-henri-pezerat.org/soutien-a-anthony-smith/ 


\section{AUTORES}

\section{ANNIE THÉBAUD-MONY}

INSERM/IRIS, Université Sorbonne Paris Nord, 74 rue marcel Cachin, 93017 - Bobigny-Cedex annie.mony@gmail.com 